\title{
Utility of the National Ignition Facility for Inertial Fusion Energy and Radiation Sciences Experiments
}

M. Tobin, V. Karpenko, R. Kauffman, A. Anderson, G. Simonson, H. Kruger, J. F. Davis, and T. Hoover

\section{AUG 169996 \\ O. STI}

This paper was prepared for submittal to the American Nuclear Society 12th Topical Meeting on the Technology of Fusion Energy

Reno, NV

June 16-20, 1996

June 14, 1996
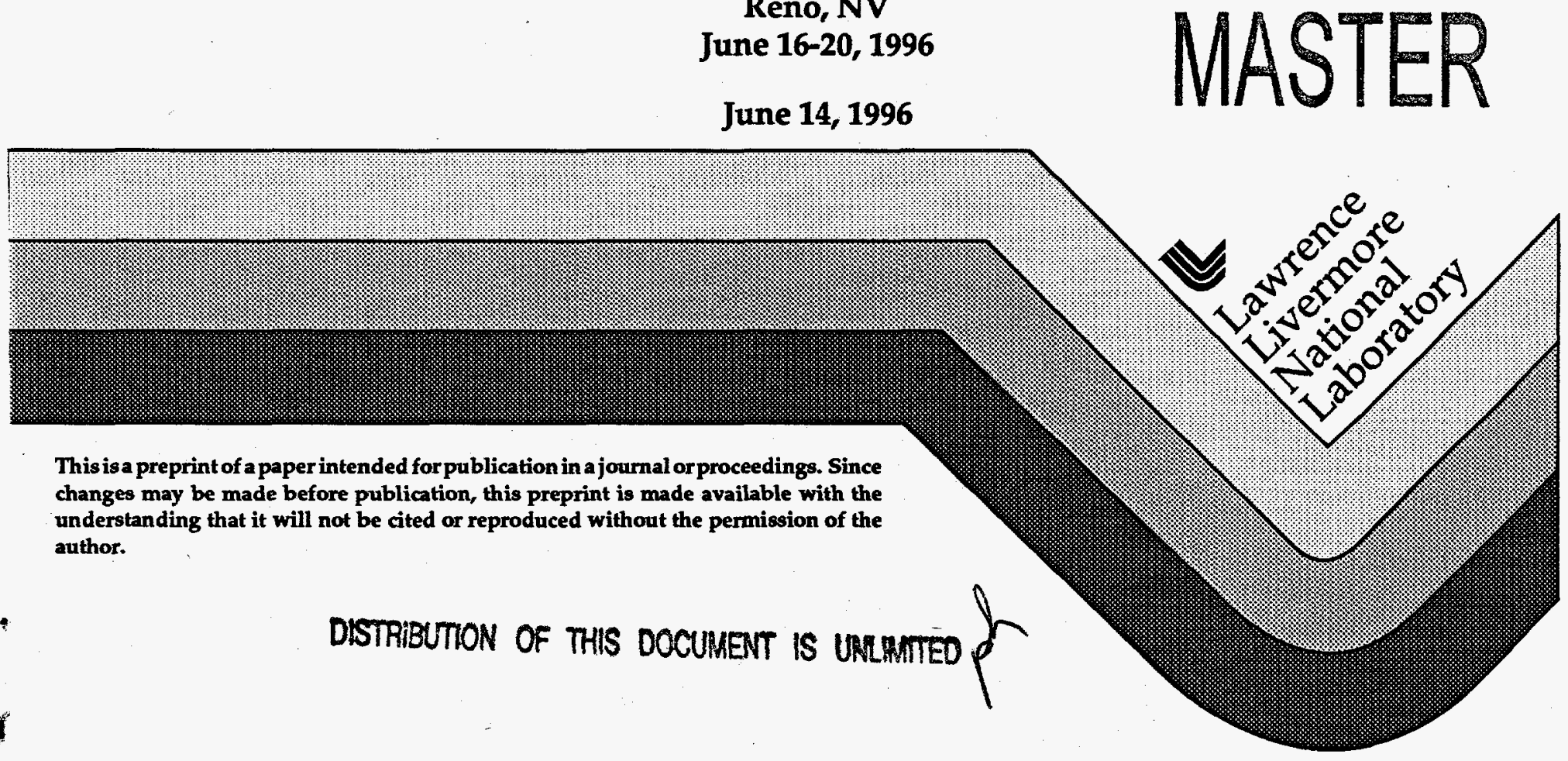


\section{DISCLAIMER}

This document was prepared as an account of work sponsored by an agency of the United States Government. Neither the United States Government nor the University of California nor any of their employees, makes any warranty, express or implied, or assumes any legal liability or responsibility for the accuracy, completeness, or usefulness of any information, apparatus, product, or process disclosed, or represents that its use would not infringe privately owned rights. Reference herein to any specific commercial product, process, or service by trade name, trademark, manufacturer, or otherwise, does not necessarily constitute or imply its endorsement, recommendation, or favoring by the United States Government or the University of California. The views and opinions of authors expressed herein do not necessarily state or reflect those of the United States Government or the University of California, and shall not be used for advertising or product endorsement purposes. 


\section{DISCLAIMER}

Portions of this document may be illegible in electronic image products. Images are produced from the best available original document. 


\title{
UTILITY OF THE NATIONAL IGNITION FACILITY FOR INERTIAL FUSION ENERGY AND RADIATION SCIENCES EXPERIMENTS
}

\author{
Lawrence Livermore National Laboratory \\ L-481, P.O. Box 5506 \\ Livermore, CA 94550 510/423-1168 \\ J. Davis \\ Alme and Associates \\ 6020 S. Richmond Hwy., Ste. 203 \\ Alexandria, VA 22303 703/329-0601 \\ T. Hoover \\ Defense Nuclear Agency \\ Virginia (?)
}

M. Tobin, V. Karpenko, R. Kauffman, A. Anderson, G. Simonson, and H. Kruger

\begin{abstract}
The NIF is being configured so as to not preclude the conduct of radiation sciences experiments that will contribute to evaluating the readiness of military systems and components to withstand radiation environments. The range of possible experimental environments and the flexibility to introduce various types of experimental packages suggests synergism with experiments related to Inertial Fusion Energy development on the NIF. The design status of NIF features to support radiation sciences experiments is described, and a relationship to their applicability to IFE experimentation on NIF is discussed.
\end{abstract}

\section{INTRODUCTION}

The benefits of a laboratory micro-fusion capability to produce unparalleled conditions of energy density will make major contributions to defense, Inertial Fusion Energy (IFE), and basic science and technology research programs. The Department of Energy is therefore proposing to construct the National Ignition Facility (NIF) by the year 2002 to embark on a program to achieve ignition and modest gain in the laboratory. The NIF will consist of a $1.8-\mathrm{MJ}, 0.35-\mu \mathrm{m}$ laser with 192 independent beamlets. This represents a 50-fold increase in laser energy over the Nova laser at Lawrence Livermore National Laboratory.

The facility represents an impressive, value-added radiation sciences experimental facility that can be used to support the national defense mission of survivability and lethality of defensive systems. The unique $x$-ray environments NIF is capable of are discussed. These experiments also may have synergy or applicability to IFE and other applications. While the achievement of ignition and gain speaks for itself in terms of its impact on developing IFE, what is less clear are the specific experiments for NIF implied by this breakthrough. There are areas of IFE development, such as fusion power technology, that would significantly benefit from NIF experiments. Many key IFE "credibility" issues can be addressed, and perhaps resolved, using the environments created in NIF, such as neutrons, $x$-rays, and debris environments with characteristics that may mimic inreactor conditions, if only for one shot. Data collected from NIF IFE experiments before, during, and after ignition may confirm predictive capabilities key to designing IFE facilities. Modeling being developed for NIF chamber design will also be applicable to IFE uses.

\section{INTEGRATION OF USER NEEDS INTO THE NATIONAL IGNITION FACILITY}

The NIF has three main missions: (1) to support nuclear weapons physics and effects, (2) to achieve ignition of both direct and indirect drive targets, and (3) to act as a 'magnet' facility for spawning research into basic energy sciences and inertial fusion energy. Inertial confinement fusion (ICF) target requirements for indirect drive ignition were the initial set of parameters that allowed a 'flow down' to NIF design specifications. The top level specifications for NIF are called Primary Criteria and Functional Requirements, such as minimum laser energy $(1.8 \mathrm{MJ})$, wavelength $(0.35 \mu \mathrm{m})$, peak power (500 TW) and target alignment $(50 \mu \mathrm{m})$, among others. After the beginning of Title I, more detailed specifications were required to support the design, and System Design Requirements were established for the Facility, Laser, Target Area, Controls, and Power Conditioning.

To consider the needs of other types of experiments that support the rest of the NIF mission, several NIF User groups produced White Papers that detailed user 
requirements for NIF.1,3,4 These included the IFE User Group and the NIF Radiation Sciences User Group (NRSUG), as well as Direct Drive, High Energy Density Sciences, and Weapons Physics User Groups.

Of the capabilities requested by the user groups, the NIF project responded by either adopting the feature directly, or by adopting the feature on a 'do not preclude' basis. The main criterion that determined whether the feature would be adopted on a 'do not preclude' basis or fully adopted, was the evaluation of the cost and schedule impact on the design and construction of NIF. For example, the addition of a large access port to the side of the chamber was deemed to be a very costly modification at a later date, compared to a much smaller cost to include it in the initial design. An example of a feature that was more appropriate to provide on a 'do not preclude' basis was the request to be able to steer individual beamlets to as much as $\pm 25 \mathrm{~cm}$ from chamber center. To support this request, the decision was made to allow the insertion at some later date of either a refractive or diffractive optic into the NIF final optics assembly to steer the beam. The development of the optic is viewed as a user-based responsibility. The result of these decisions was that the NIF's utility and flexibility were greatly increased. In the area of Radiation Sciences, we describe the requested features, how the project has responded to the requests with design modifications, and how these changes substantially support the IFE user requests and possible experimentation. The description of how the NIF has been re-configured to preserve the ability to do these different types of experiments is useful to those who will consider the use of the NIF for IFE experimentation, as there is significant synergy between introducing potentially large experimental packages and arranging for their exposure to a radiation environment-whether the purpose is to evaluate the 'hardness' of a military system or to evaluate the material response as it may apply to the interior of an IFE power plant chamber.

\section{USE OF NIF FOR RADIATION SCIENCES EXPERIMENTS, AND BENEFITS FOR IFE EXPERIMENTS}

Radiation sciences experiments will involve the use of $x$ rays and possibly neutrons to create environments useful in evaluating the response of certain systems or components of systems to the radiation environments they may encounter in their application, either in space or in a military engagement. The cessation of underground testing has prevented creating some of the required environments for this purpose. The NIF represents the potential to recover some portion of the lost testing capability.
$\mathrm{X}$-ray tests would be conducted by using the laser alone or using the $\mathrm{x}$-ray emission from the hohlraum wall with yields of up to $20 \mathrm{MJ}$. The laser-only $\mathrm{x}$-ray tests utilize three types of targets: high- $Z$ disks, thin-membrane bags filled with a gas such as Xe, and hohlraums. The gas bags become underdense plasmas when irradiated at $10^{14}$ to $1015 \mathrm{~W} / \mathrm{cm}^{2}$ and efficiently emit $\mathrm{x}$ rays useful to effects testing. First surfaces in IFE power plants may see $x$-ray fluences of up to a few tens of joules per square centimeter, up to $\sim 1-\mathrm{keV}$ photon energies, and pulse lengths of a few tens of ns. Of greatest relevance to potential IFE testing, therefore, is the ability for NIF to generate similar $\mathrm{x}$-ray conditions. Studies supporting radiation science experiments suggest that achieving a quasi-continuum 0.1 - to $2-\mathrm{keV}$ spectra of $\sim 20 \mathrm{~J} / \mathrm{cm}^{2}$ with pulse lengths of up to $20 \mathrm{~ns}$ or more over an area of $\sim 1500 \mathrm{~cm}^{2}$ is possible. NIF requirements to support such an experiment (requested by the Radiation Sciences User Group) include the ability to steer beams to $\pm 5 \mathrm{~cm}$ of chamber center to engage an array of disk or gas bag targets up to $10 \mathrm{~cm}$ wide with staggered 3- to 4-ns pulse length beams. Delaying arrival times by up to $20 \mathrm{~ns}$ from first to last beam allows creating a $>80 \%$ uniform $x$-ray fluence to the specifications listed above. Expanding the beam steering capability to $\pm 25 \mathrm{~cm}$ expands the area available by a factor of 3 to 4 if the test surface is in the near field of the resulting planar source.

Accommodations have been requested to support the introduction of testing assemblies up to a port located on the waist of the chamber, and to the bottom access port. For the waist port, these assemblies can be as large as 2.5-m diameter and 7-m long, weighing up to 5 tons. For the bottom port, these assemblies can be as large as 2-m diameter and 3-m long, with a weight up to 15 tons. A lift set into the chamber pedestal will be used to raise such a package into the chamber. Facility design includes features to allow access of packages of these sizes to the third and bottom floor, respectively, of the Target Bay. To accommodate these large sizes, a special port has been designed into the NIF chamber, at the waist, facing toward the diagnostics building, which is at the rear of the Laser and Target Area Building, to most effectively accommodate large assemblies into the building through this rear access. The unusual shape of this port (an oval or oblong shape) is due to the location of a direct drive port in the vicinity. The requirement for $1.5-\mathrm{m}$ clear access is met with such a shape; however, direct drive experiments and the full use of this port will be incompatible.

This has relevance to proposed IFE experiments. Initial planning of possible experiments to examine isochoric heating and various film protection of first walls or piping, and chamber clearing experiments assumed that 
such experiments would be limited by the size of the NIF diagnostic manipulator tube, $-25 \mathrm{~cm}$ in diameter. The much greater envelope required by Radiation Sciences Users affords greater flexibility in the design and conduct of such experiments. Additionally, proposals for such IFE test assemblies as the frost mini-chamber, 2 which would require access through a bottom port, are also possible under the radiation sciences experiments' 'envelope.'

Two conventional facility modifications have also been requested that are of note. First, a $100 \mathrm{~m}^{2}$ screen room has been requested and space allocated to support the set up, check out, and fielding of Radiation Sciences experiments. The similarities between Radiation Sciences and IFE experiments, such as the use of specially tailored sources to create conditions to be diagnosed at late time in a separate volume/area from chamber center/source location, suggest that there may be some overlap of screen room needs between Radiation Sciences and IFE. Grounding and shielding specifications requested for Radiation Sciences experiments, such as establishing electronic isolation between the Target Bay and Laser Bay, will also aid in making such late-time measurements. Second, provisions for a 'hot cell' area for the 'cool down' of experimental packages will be equally beneficial to both Radiation Sciences and IFE experiments.

\section{USE OF NIF FOR OTHER INERTIAL FUSION ENERGY EXPERIMENTS}

Target physics issues for IFE can be substantially addressed on NIF for either laser or ion targets, as has been previously reported. ${ }^{1}$ This will include investigations for direct drive target physics as well as indirect drive, because NIF will have a capability to be converted to direct drive experiments.

One type of target systems experiments proposed includes the ability to fire the laser in four staggered 48beamlet shots spaced $200 \mathrm{~ms}$ apart, in order to support sequential target dropping/injection studies. These experiments would require symmetry in order to use subignition neutron yields as a diagnostic. However, the current design of the NIF laser will not allow such large spacing between shots, since the flash lamps all fire at the same time. The largest spacing possible from the beginning of the first pulse (group of $4 \times 2$ beams) to the end of the last pulse is $\sim 100 \mathrm{~ns}$.

Large Radiation Science experiments would be contained in a large apparatus called a Test Object Transport and Insertion Module, or TOTIM (see Fig. 1). Such equipment, containing both the test item and the diagnostic to measure its response to radiation, can be equally useful in the implementation of so-called Target Chamber Dynamics and Fusion Power Technology experiments, as outlined in reference 1. These experiments call for liquid jets or wetted-wall IFE schemes to be examined on a one-shot basis in NIF radiation environments of neutrons, $x$ rays, and debris, where the test item is within tens of centimeters of yield targets. While significant effort is of course required to design survivable test canisters for these cases, the waist and bottom port openings to the NIF chamber ensure there will be access for such experiments.

\section{UTILITY OF NIF CHAMBER DYNAMICS' PREDICTIVE CAPABILITIES FOR IFE}

Target chamber design for the NIF must ensure that all performance requirements are met, with survival of the final optics as the primary goal. Modeling predictions are required for the amount, composition, and physical form of material deposited on debris shields following a shot in the NIF target chamber. This is a very complicated problem that involves material ablation and the resulting gas dynamics of several different vapor species, coupled with the possibility of particle formation during the expansion of this vapor throughout the chamber. The tools under development for resolving these issues for NIF will also be available for similar concerns with IFE reactor chambers.

The ABLATOR code was developed to determine the starting point for NIF optics threat calculation, i.e., the ablation of materials by high fluences of $x$ rays. Four processes are included in the finite-difference ablation model to accomplish this goal. The first aspect is the energy deposition from the $\mathrm{x}$ rays through the thin surface layers of material. A transient thermal conduction model allows this energy to move between zones, which is particularly important near the strongly heated surface layers. Heating causes thermal expansion, which raises pressures and causes hydrodynamic motion as the pressures release from the surface. The fourth part of the model describes the removal of material through surface vaporization and the initial stages of the expansion into the chamber. Ablation depths predicted by this code have been experimentally validated for such materials as fused silica that ablate by simple vaporization. 5

The TSUNAMI code provides the basis for the targetchamber gas dynamics' predictions. ${ }^{6}$ This 2-D Eulerian code can model the relevant geometries in the chamber. It will track vapor motion from ablating surfaces through to the deposition on either the chamber walls or optics assemblies. High-order Godunov finite difference techniques ensure accurate, rapid solutions. Real gas 
equations of state can be included, as these are important for dissociation, ionization, and eventual condensation of species.

The third aspect of the Chamber Dynamics tools is the means to track the average amount and composition of any ablated material, in particular to model possible condensation into particles before reaching the final optics. To give even a crudely realistic treatment of this problem, gas phase equations of state (EOS) for the multicomponent gas mixtures are required. Such an EOS has been developed for fused silica, which will be ablated from the NIF beam dumps. ${ }^{7}$ Although the vapor is atomically $\mathrm{SiO}_{2}$ in composition, the molecular composition of this vapor can vary considerably from being nearly atomic $\mathrm{Si}$ and $O$ at high temperature and low density, to being heavily molecular $\mathrm{SiO}_{2}$ at low temperature and high density. At intermediate conditions, high concentrations of molecular $\mathrm{SiO}$ and $\mathrm{O}_{2}$ are present. An EOS incorporating these features has been developed into a set of SESAMEstyle tables, 8 which will then be utilized by the TSUNAMI code. A subroutine that uses the thermodynamic and dynamic state information generated by the TSUNAMI code will then update the number of particles present (if any) and their average size. These particles will not influence the hydrodynamic behavior of the expanding vapor except through the consumption of vapor during particle formation and growth. Transport and deposition of the vapor and particles to the optics will then determine the severity of this threat.

\section{CONCLUSIONS}

Radiation Sciences users for NIF have requested many features that are synergistic with the range of IFE experiments proposed in the areas of Chamber Dynamics and Fusion Power Technology. Large access ports at the waist and bottom of the NIF chamber afford access to integral test packages, where test items can be both exposed to radiation and their response measured. X-ray environments possible in support of weapons effects testing may also be useful for examining wetted-wall or liquid-jet response due to similarities of x-ray characteristics such as spectrum, pulse length, and fluence. Chamber dynamics' predictive capabilities being developed to support optics protection for NIF may be equally useful in predicting chamber clearing for IFE chambers.

This work was performed under the auspices of the U.S. Department of Energy by Lawrence Livermore National Laboratory under Contract No. W-7405-Eng-48.

\section{REFERENCES}

1. B.G. Logan, M. Tobin, and W. Meier, The Role of the National Ignition Facility in the Development of Inertial Fusion Energy, Lawrence Livermore National Laboratory, Livermore, California, UCRL-ID-119383 (April 1995).

2. J. Scott and P. Peterson, "The Mini-Chamber, an Advanced Protection Concept for NIF," this conference.

3. J. Davis, Status of Facilitization of the NIF for Radiation Sciences, Interim Report for Subcontract B328324, Alme and Associates, Alexandria, Virginia (May 1996).

4. T. Perry and B. Wilde, NIF System-Design Requirements for Nuclear-Weapons Physics Experiments, Lawrence Livermore National Laboratory, Livermore, California, UCRL-ID-120738, L-20072-1 (April 1995).

5. A. Anderson, A. Burnham, M. Tobin, and P. Peterson, "Modeling and Experiments of X-ray Ablation of NIF First Wall Materials," this conference.

6. J.C. Liu, X.M. Chen, V.E. Shrock, and P.F. Peterson, TSUNAMI 1.0: A Program for Predicting Gas Dynamics in Inertial Confinement Fusion Reactors, University of California Berkeley, Berkeley, California, UCB-NE-4199 (1992).

7. G. Wilemski, "Silica Vapor Pressure and Energy Calculations," Lawrence Livermore National Laboratory, Livermore, California, LLNL Technical Memo, TAT \#96-008.2, March 22, 1996.

8. K.S. Holian, T-4 Handbook Of Material Properties Data Bases, Los Alamos National Laboratory, Los Alamos, New Mexico, LA-10160-MS (1984). 


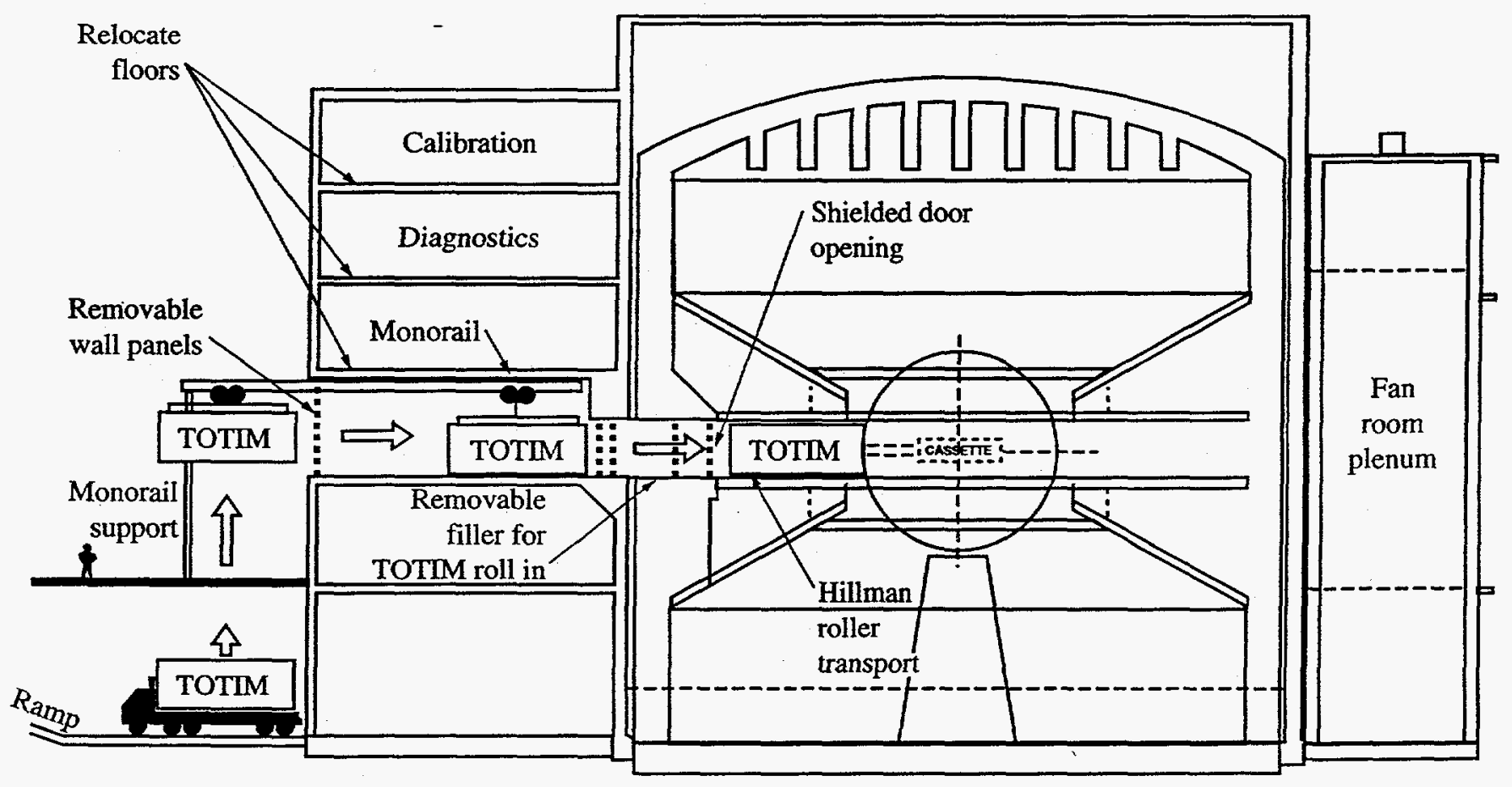

Fig. 1. NRSUG concept for experiments is to use a test object transport and insertion module (TOTLM) to mate the experiment to the chamber.

40-00-0496-0686Apb01 